\title{
Universal or Selective: That's the Question in Screening of Developmental Dysplasia of the Hip
}

\section{Gelişimsel Kalça Displazisi Taraması: Evrensel ya da Seçici?}

\section{(1) Deniz ÇANKAYA', (1) Mehmet Yekta ÖNCEL²}

${ }^{1}$ University of Health Sciences Turkey, Gülhane Training and Research Hospital, Clinic of Orthopaedic and Traumatology, Ankara, Turkey

${ }^{2}$ İzmir Kâtip Çelebi University Faculty of Medicine, Division of Neonatology, İzmir, Turkey

Cite as: Çankaya D, Öncel MY. Universal or Selective: That's the Question in Screening of Developmental Dysplasia of the Hip. Forbes J Med. 2021;2(3):140-141.

Keywords: Developmental dysplasia, hip, newborn, screening, ultrasound

Developmental dysplasia of the hip (DDH) is one of the main public health problems in newborns as it is the most common congenital disease of the musculoskeletal system in those ages. ${ }^{1-3}$ As a definition, it represents a broad spectrum of pathological hip and affected proximal femur and acetabulum resulting in malalignment of the femoral head and the acetabulum with disproportionate growth. ${ }^{4.5}$ Early detection and intervention are crucial in preventing dysplasia of the hip, because the condition may be initially occult and it is easily treated when caught early, but difficult to treat later. ${ }^{2}$ Therefore, there are various screening programs from birth and Turkey has its national screening programs for newborns. ${ }^{6}$

The physical examination including instability maneuvers such as Barlow and Ortolani maneuvers should be done universally. Clinician tries to dislocate the femoral head with hip adduction and posterior translation during the Barlow maneuver and tries to relocate a dislocated femoral head with hip abduction and anterior translation in the Ortolani maneuver. ${ }^{2.3 .5}$ However, physical examination seems to fail in detecting all cases of hip dysplasia, therefore ultrasound has been becoming the primary imaging modality for diagnosing DDH in newborns during the last decades. ${ }^{13,6}$ In a recent study investigating the utility of ultrasonographic findings in predicting the subsequent radiographic parameters of DDHs, the ultrasonographic parameters showed an excellent negative predictive value for an abnormal femoral head position on radiographs. ${ }^{4}$

Graf ultrasound method is the most popular ultrasound screening method, a hip with an alpha angle $>60$ degrees and beta angle $<50$ degrees is classified as normal in this method. ${ }^{1.4}$ After acceptance of the Graf ultrasound method worldwide, various ultrasound screening programs have been performed in different countries. In the selective screening program, only newborns with abnormal physical examination and risk factors are screened Graf ultrasound method and all newborns are screened in the universal screening program. Countries such as Turkey, England, and United States have selective screening programs, whereas Austria and Germany have universal screening programs. ${ }^{6-8}$ 
The universal screening program is criticized as it potentially causes higher rates of treatment with abduction splinting, high costs, unnecessary treatment, and increased posttreatment complications of avascular necrosis.1.3.8 The selective screening program is shown to cause late diagnosed $\mathrm{DDH}^{7}$ and this later diagnosis leads to invasive surgical procedures such as total hip arthroplasty. The hospital cost of total hip arthroplasty is higher in patients with DDH compared with primary osteoarthritis and increased severity of dysplasia is associated with higher costs. ${ }^{9}$

In a conclusion, DDH is still one of the main public health problems in neonates. Despite the many studies focusing on ultrasound screening programs for decades, no consensus has been reached about routine ultrasound screening of the hip in neonates. Due to the increased number of children treated for DDH, there is a concern about overtreatment for the universal ultrasound-screening program. In contrast, late detected cases resulting in coxarthrosis are the main concern regarding the selective ultrasound screening of the hip in neonates. Therefore, every country has its ultrasoundscreening program, and Turkey has her own successful selective national ultrasound-screening program for decades. New studies and updates of the literature should be regularly evaluated to maintain and improve the current successful national ultrasound screening program.

\section{References}

1. Quader N, Schaeffer EK, Hodgson AJ, Abugharbieh R, Mulpuri K. A Systematic Review and Meta-analysis on the Reproducibility of Ultrasound-based Metrics for Assessing Developmental Dysplasia of the Hip. J Pediatr Orthop. 2018;38:e305-11.

2. Schwend RM, Shaw BA, Segal LS. Evaluation and treatment of developmental hip dysplasia in the newborn and infant. Pediatr Clin North Am. 2014;61:1095-107.

3. Vaquero-Picado A, González-Morán G, Garay EG, Moraleda L. Developmental dysplasia of the hip: update of management. EFORT Open Rev. 2019;4:548-56.

4. Tan SHS, Wu CH, Wong KL, Hui JH. Correlations between ultrasonographic and subsequent radiographic findings of developmental dysplasia of the hips. Ultrasonography. 2019;38:43-51.

5. Laborie LB, Markestad TJ, Davidsen H, et al. Selective ultrasound screening for developmental hip dysplasia: effect on management and late detected cases. A prospective survey during 1991-2006. Pediatr Radiol. 2014;44:410-24.

6. T.C. Sağlık Bakanlığı. Halk Sağlığı Genel Müdürlüğü. GKD akış şeması. Erişim adresi: https://hsgm.saglik.gov.tr/depo/birimler/ cocuk_ergen_db/GKD_akis_semasi.pdf

7. Broadhurst C, Rhodes AML, Harper P, Perry DC, Clarke NMP, Aarvold A. What is the incidence of late detection of developmental dysplasia of the hip in England?: a 26-year national study of children diagnosed after the age of one. Bone Joint J. 2019;101-B:281-7.

8. Wilf-Miron R, Kuint J, Peled R, Cohen A, Porath A. Utilization of ultrasonography to detect developmental dysplasia of the hip: when reality turns selective screening into universal use. BMC Pediatr. 2017:17:136.

9. Ashraf A, Larson AN, Maradit-Kremers H, Kremers WK, Lewallen DG. Hospital costs of total hip arthroplasty for developmental dysplasia of the hip. Clin Orthop Relat Res. 2014;472:2237-44. 